\title{
Return to Sport After Patellar Tendon Rupture: a Systematic Review
}

\author{
J. Grondin ${ }^{1}$, P. Menu11,2,3, T. Garraud ${ }^{4}$, O. Mesland ${ }^{1,2}$, M. Dauty ${ }^{1,2,3}$, A. Fouasson-Chailloux ${ }^{1,2,3}$ \\ 1 CHU Nantes, Physical Medicine and Rehabilitation Center, University Hospital of Nantes, France \\ 2 CHU Nantes, Service de Médecine du Sport, University Hospital of Nantes, France \\ 3 INSERM UMR U1229/RMeS, Regenerative Medicine and Skeleton, Nantes University \\ ONIRIS, Nantes, F-44042, France \\ ${ }^{4}$ CHU Nantes, Rheumatologic department, University Hospital of Nantes, France
}

\section{CORRESPONDING AUTHOR:}

Alban Fouasson-Chailloux

MPR Locomotrice et Respiratoire

CHU de Nantes, Hôpital St Jacques

85 rue Saint Jacques

44093 Nantes, Cedex 1

E-mail: alban.fouassonchailloux@chu-nantes.fr

Phone: +33240846 211

DOI:

10.32098/mltj.04.2019.05

LEVEL OF EVIDENCE: 4

\begin{abstract}
SUMMARY
Background. Patellar tendon rupture is a rare and disabling injury that may occur during sport practice and is considered as the $4^{\text {th }}$ stage of the Blazina's classification of jumper's knee. Return to sport after patellar tendon rupture has not been clearly assessed. Methods. Medical databases were screened, and article research extended from 1980 to April 2019. The inclusion criteria were report of more than 2 cases of isolated and complete uni- or bilateral patellar tendon rupture, patients over 18. Studies that did not specify patients' ability to return to sport were excluded.

Results. Nine studies, 196 patients and 202 patellar tendon ruptures were included. Mean follow-up ranged from 24 to 111.5 months and return to sport ranged from 52 to $100 \%$. Crucial data were often lacking, such as the type of sport practiced, the pre-injury level of sport, and the delay of return to sport. A high proportion of patients did not report any medical history that could have weakened their patellar tendon before the rupture.

Conclusions. The rate of return to sport seems good but our conclusions are restricted due to the studies' low level of evidence. It highlights the need of a standardized report of specific data.
\end{abstract}

\section{KEY WORDS}

patellar tendon; injury; rebabilitation; physical activity

\section{INTRODUCTION}

Rupture of the patellar tendon is a very rare injury, its incidence is estimated at $0.68 / 100000$ in the general population (1), 6 times less frequent than patellar fractures (2). It concerns only $0.6 \%$ of all tendinous ruptures (3). Although infrequent, the consequences of patellar tendon rupture can be particularly serious and responsible for disability (4). In sport traumatology, patellar tendon rupture is generally considered as the $4^{\text {th }}$ stage of the Blazina's classification of jumper's knee (5). Jumper's knee, that can be classified in overuse injuries, frequently affects professional athletes who have to perform repetitive jumps and changes of direction, with a prevalence estimated at $44 \%$ in volleyball players, $31 \%$ in basketball players and 5 to $10 \%$ in soccer players (6). However, only $5 \%$ of the patients with patellar tendon rupture have a history of patellar tendinopathy (4). Indeed, the role of sport in this injury is not limited to a jumper's knee history, but also concerns the circumstances of the rupture. In fact, patellar tendon ruptures occur in 32 to $57 \%$ of the cases during sport practice $(1,7,8)$. The mechanism is either indirect (sudden and eccentric contraction of the quadriceps muscle), either direct (violent impact against the patellar tendon) (1). Surgical treatment is needed to restore the mechanical properties of the knee extensors (4). A healing time of several weeks is imperative, generally followed by a rehabilitation program (9). It is responsible for a long period of sports unavailability, which is a problem, especially in high-level or professional athletes. There 
is a lack of data in sports medicine literature concerning the epidemiology of this injury but also concerning its postoperative management and particularly its consequences in terms of return to sport.

So, we aimed to perform a systematic review to assess the epidemiology, the post-operative management and the consequences in terms of return to sport after patellar tendon rupture.

\section{MATERIAL AND METHODS}

\section{Study eligibility}

We searched articles in the medical databases: PubMed, Cochrane database, ScienceDirect and Google Scholar. Article research extended from January 1980 to April 2019. Only studies in English language were selected. Multiple searches were carried out using the following MeSH: « patellar tendon » AND « rupture » AND « repair » AND « sport ». On google scholar database, it was necessary to define the exact expression « patellar tendon rupture ». The search was performed independently by 2 assessors (JG, AFC) to assess titles and abstracts of potentially relevant articles, and then the full-text articles were retrieved. In case of doubt, a third assessor's advice was asked (MD). After identification of key articles, their reference and citation lists were perused for further information sources. The inclusion criteria were: report of more than 2 cases of isolated and complete uni- or bilateral patellar tendon rupture, in patients over 18 years old. Patellar tendon ruptures asso- ciated with another injury (LCA, patella fracture, quadriceps tendon rupture) were not included. We excluded from the review the studies that did not specify patients' ability to return to sport and those mentioning a functional scoring system like Cincinnati knee rating scale but without details about the sports items ${ }^{10}$. Articles mentioning a case of patellar tendon rupture after a total knee arthroplasty were also excluded. We excluded cases of ruptures occurring in patients with rheumatoid arthritis or systemic lupus, and other metabolic risk factors such as diabetes, gout and severe renal failure (11).

\section{Quality analysis}

We used PRISMA guidelines for this review (12). The included studies were critically appraised using GRADE approach, in order to evaluate the study quality of evidence (13). We also used the Modified Coleman Methodology score (MCMS) (14) which is known to assess the design of studies dealing with orthopaedic treatments (16).

\section{RESULTS}

\section{Study selection}

Out of the 804 records, we retained 95 articles, and, after assessing full-text articles, we excluded 85 of them because of exclusion criteria (figure 1). We finally included 9 original articles representing 196 patients. The articles were all series of cases with small sample size from 4 to 37 patients.

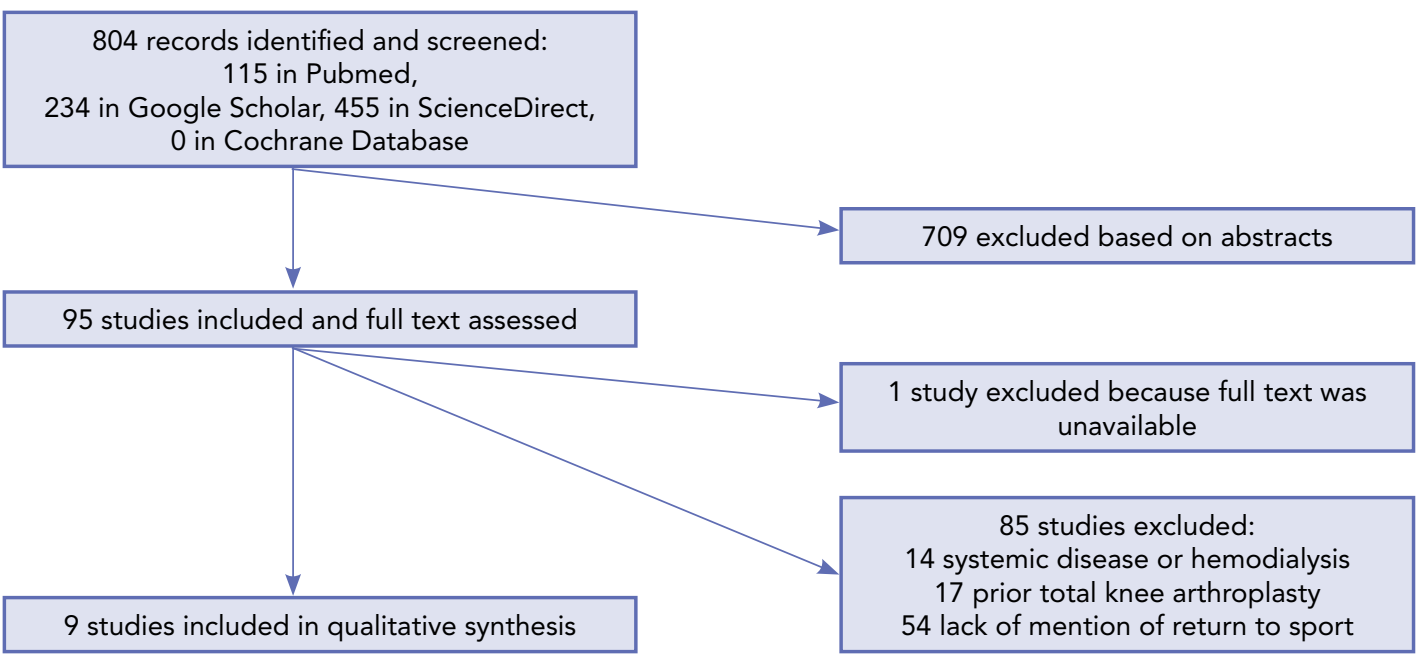

Figure 1. Flow diagram. 
The classification of their level of evidence according to the GRADE approach arises important limitations regarding study design, sample size, and consistency of the results. The MCMS ranged from 16 to 36 , which is considered as a poor rate $(<54$ points) (table I).

\section{Demographic data}

Amongst 196 patients, 14 were females, 182 were males. Mean age ranged from 26 years old (17) to 42.6 years old (17) (table II). In one article which included 66 patients, mean age was not specified (18). There were 202 patellar tendon ruptures, including 6 cases of bilateral ruptures. Rupture occurred from 37 to $100 \%$ of cases during sport practice (table III). Main other circumstances of rupture were vehicle accidents and falls.

\section{Type of Sports and level of practice}

Amongst sport traumatisms, basketball was the most frequent $(32$ cases), then football $(23$ cases) and soccer $(9$ cases) (table III). Pre-injury level of sport was specified in 4 studies (table II): Boublik et al. reported 24 professional football athlete (17), Maffuli et al. reported 8 recreational athletes (19), Marder et al. reported 1 professional, 2 collegiate, 3 competitive recreational and 9 recreational athletes (20), Kuechle et al. reported 1 high school basketball player and 4 recreational athletes (21).

\section{Patellar tendon medical history}

Many risk factors are reported in literature, such as gout, renal failure, and diabetes mellitus (11) that may induce patellar tendon ruptures in a non-athletic population. So, we excluded studies that mentioned these factors, and focused on the medical history relevant to an athletic population. Therefore, we focused on 3 items, that may weaken a patellar tendon before its rupture: anterior knee pain or patellar tendinopathy history (5), prior knee injury, and steroid use (22). These features were not systematically reported in the articles, and moreover, in most articles we could not determine if the patients that presented anterior knee pain were also those with prior knee injury or steroid use. However, we observed that there was a wide proportion of patients that did not report any medical history that could have weakened their patellar tendon. Boublik et al. reported 22 professional football players that suffered from patellar tendon ruptures, but only 11 of them reported previous anterior knee pain or steroid use (table III) (17).

\section{Follow-up and return to sport}

132 patients were available for a long-term follow-up (table III). Mean follow-up was widely variable: from 24 to 111.5 months. During this follow-up, return to sport was usually reported, but not the delay. Only Marder et al. reported the delay to return to sport which ranged from 5 to 15 months

Table I. Evaluation of the level of evidence using Modified Coleman Methodology Score and GRADE approach.

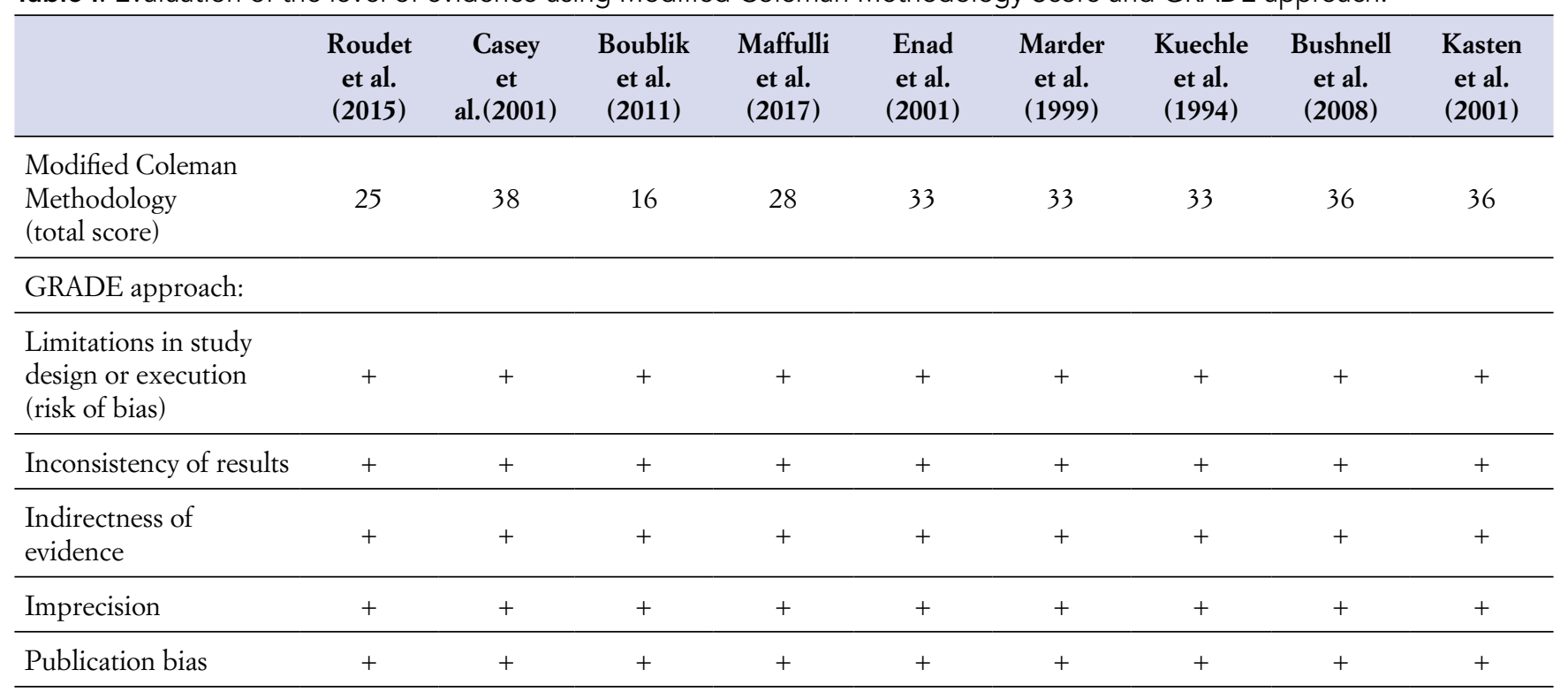

Abbreviations: +: high risk of bias; -: low risk of bias 
Table II. Demographic data and management of the tendon rupture (type of surgery and rehabilitation protocol).

\begin{tabular}{|c|c|c|c|c|c|c|c|}
\hline Studies & Patients & $\begin{array}{c}\text { Age } \\
\text { (years) }\end{array}$ & $\begin{array}{c}\text { Sex } \\
(\mathrm{M} / \mathrm{F})\end{array}$ & $\begin{array}{l}\text { Ruptures } \\
\text { (bilateral) }\end{array}$ & $\begin{array}{l}\text { Delay of } \\
\text { surgery }\end{array}$ & Type of surgery & Rehabilitation protocol \\
\hline $\begin{array}{l}\text { Roudet et al. } \\
\text { (2015) }\end{array}$ & 37 & 42,6 & $33 / 4$ & $38(1)$ & Acute & $\begin{array}{l}15 \text { end-to-end sutures, } 19 \text { trans- } \\
\text { osseous drill holes, } \\
4 \text { anchors sutures, } 36 \\
\text { reinforcements by cerclage wire }\end{array}$ & $\begin{array}{l}\text { Late mobilization, post- } \\
\text { operative full weight } \\
\text { bearing }\end{array}$ \\
\hline $\begin{array}{l}\text { Casey et al. } \\
(2001)\end{array}$ & 4 & 29 & $4 / 0$ & 4 & Chronic & Suture and cerclage wire & $\begin{array}{l}\text { Early mobilization and } \\
\text { early full weight bearing }\end{array}$ \\
\hline $\begin{array}{l}\text { Boublik et al. } \\
\text { (2011) }\end{array}$ & 22 & 26 & $22 / 0$ & $24(2)$ & Acute & $\begin{array}{l}\text { Direct repairs techniques, } 1 \\
\text { reinforcement by Dall-Miles cable, } \\
\text { one augmentation with semi- } \\
\text { tendinosus }\end{array}$ & $\begin{array}{l}\text { Personalized protocols } \\
\text { not clearly defined }\end{array}$ \\
\hline $\begin{array}{l}\text { Maffulli et al. } \\
\text { (2017) }\end{array}$ & 19 & 46 & $16 / 3$ & 19 & Chronic & $\begin{array}{l}\text { Reconstruction using semi- } \\
\text { tendinosus and gracilis grafts }\end{array}$ & Not mentioned \\
\hline $\begin{array}{l}\text { Enad et al. } \\
(2001)\end{array}$ & 13 & 37 & $13 / 0$ & 13 & $\begin{array}{c}<3 \\
\text { weeks }\end{array}$ & $\begin{array}{l}\text { Trans- osseous drill holes, } \\
\text { reinforcement by cerclage }\end{array}$ & $\begin{array}{l}\text { Early mobilization and } \\
\text { early full weight bearing }\end{array}$ \\
\hline $\begin{array}{l}\text { Marder et al. } \\
\text { (1999) }\end{array}$ & 15 & 33 & $15 / 0$ & 15 & Acute & $\begin{array}{l}\text { Trans-osseous drill holes for } \\
\text { proximal avulsions, end-to-end } \\
\text { sutures for mid-portion ruptures }\end{array}$ & $\begin{array}{l}\text { Early mobilization and } \\
\text { early full weight bearing }\end{array}$ \\
\hline $\begin{array}{l}\text { Kuechle et al. } \\
\text { (1994) }\end{array}$ & 5 & 36 & $5 / 0$ & $6(1)$ & Acute & $\begin{array}{l}\text { Trans-osseous drill holes for } \\
\text { proximal avulsions, end-to-end } \\
\text { sutures for mid-portion ruptures, } \\
\text { reinforcement by Dacron cerclage } \\
\text { for mid-portion ruptures }\end{array}$ & $\begin{array}{l}\text { Late mobilization, post- } \\
\text { operative partial weight } \\
\text { bearing }\end{array}$ \\
\hline $\begin{array}{l}\text { Bushnell et al. } \\
\text { (2008) }\end{array}$ & 15 & 34 & $?$ & 15 & Acute & Suture anchors & $\begin{array}{l}\text { Early mobilization, no } \\
\text { weight bearing for } 2 \\
\text { weeks }\end{array}$ \\
\hline $\begin{array}{l}\text { Kasten et al. } \\
\quad(2001)\end{array}$ & 66 & $?$ & $59 / 7$ & $68(2)$ & Acute & $\begin{array}{l}\text { End-to-end sutures, reinforcement } \\
\text { with wire cerclage or PDS cord }\end{array}$ & $\begin{array}{l}\text { Early mobilization and } \\
\text { early full weight bearing }\end{array}$ \\
\hline
\end{tabular}

(14 patients) (20). Boublik et al. reported that every professional football player had participated in a training camp, the season after the injury, but only 2 of them were able to play the season they got injured (17).

Return to sport ranged from 52 to 100\% (table III). Level of return to play could be assessed only in the 4 articles that mentioned pre-injury level of sport. Boublik et al. reported the cases of 22 professional football players that all returned to sport, and 19 of them returned to their pre-injury level (17). Maffulli et al. reported 3 patients out of 8 (recreational pre-injury level) who did not return to sport, whose type was not mentioned, one because of persistent knee pain, and 2 because the patients felt uncomfortable with their knee(19). Marder et al. mentioned that 6 patients with a competitive level of practice returned to their pre-injury level, and 6 out of 8 with a recreational level of practice returned to their pre-injury level (2 returned at a lower level) (20). Kuechle et al. reported cases of 5 patients, that all returned to their pre-injury level of sport (1 high-school basketball player, 4 recreational players $(21)$.

\section{Rehabilitation protocol}

Rehabilitation protocol was specified in 7 articles. In 5 articles, patients were treated with an early mobilization, before 6 weeks after surgery (table III). In 6 articles, partial weight-bearing was allowed post-operatively, whereas in one article, weight bearing was forbidden for 2 weeks.

Four studies described a re-athletization protocol $(8,20,21$, $23)$. Two of them allowed stationary bicycle between 8 to 12 weeks $(20,23)$. Concerning running activities, 1 article mentioned a delay of 12 weeks (23) and 1 a delay of 16 to 20 weeks (21). Two articles stated a delay of at least 6 months before practicing any jumps and pivoting or contact sports $(20,21)$. In 1 article, the return to any sport activity was delayed for 6 months (8). 
Table III. Pre-injury level of sport practice and medical history.

\begin{tabular}{|c|c|c|c|c|c|c|}
\hline \multirow[b]{2}{*}{ Studies } & \multirow[b]{2}{*}{$\begin{array}{l}\text { Ruptures during } \\
\text { sport practice } \\
\text { (\%) }\end{array}$} & \multirow[b]{2}{*}{ Type of sport (n) } & \multirow[b]{2}{*}{ Pre-injury level } & \multicolumn{3}{|c|}{ Medical history } \\
\hline & & & & $\begin{array}{c}\text { Anterior } \\
\text { knee pain/ } \\
\text { patellar } \\
\text { tendinopathy }\end{array}$ & $\begin{array}{l}\text { Prior knee } \\
\text { injury }\end{array}$ & $\begin{array}{c}\text { Steroid } \\
\text { use }\end{array}$ \\
\hline Roudet et al. (2015) & $21(57 \%)$ & $?$ & $?$ & 4 & $?$ & 3 \\
\hline Casey et al. (2001) & $?$ & $?$ & $?$ & 0 & 1 & 0 \\
\hline Boublik et al. (2011) & $24(100 \%)$ & $\begin{array}{l}\text { football (22) } \\
\text { basketball (1) } \\
\text { strengthening (1) }\end{array}$ & professional & 11 & 0 & 1 \\
\hline Maffulli et al. (2017) & $?$ & $?$ & Recreational & $?$ & 6 & $?$ \\
\hline Enad et al. (2001) & $12(92 \%)$ & basketball (12) & $?$ & 10 & $?$ & 0 \\
\hline Marder et al. (1999) & $10(67 \%)$ & $\begin{array}{l}\text { basketball (5) } \\
\text { volleyball (1) } \\
\text { football (1) } \\
\text { diving (1) } \\
\text { baseball (1) } \\
\text { motorcycling (1) }\end{array}$ & $\begin{array}{l}1 \text { professional and } 2 \\
\text { collegiate athletes } \\
12 \text { recreational }\end{array}$ & 6 & $?$ & 2 \\
\hline Kuechle et al. (1994) & $6(100 \%)$ & $\begin{array}{l}\text { basketball (4) } \\
\text { softball (2) }\end{array}$ & $\begin{array}{l}1 \text { high school basketball } \\
\text { player } \\
4 \text { recreational athletes }\end{array}$ & 3 & 1 & 1 \\
\hline Bushnell et al. (2008) & $10(67 \%)$ & basketball (10) & $?$ & 1 & $?$ & 1 \\
\hline Kasten et al. (2001) & $25(37 \%)$ & $\begin{array}{l}\text { soccer (9) } \\
\text { not specified (16) }\end{array}$ & $?$ & 0 & 11 & 1 \\
\hline
\end{tabular}

\section{Complementary evaluation criteria}

We also assessed criteria such as range of motion, functional scores and radiographic evaluations (Insall-Salvati index (24), Caton-Deschamp Index (25)) (table IV).

Four studies mentioned a radiographic assessment (7, 19, 20, 23): three of them were in the normal range (0.81.2 for Insall-Salvati IndeX (24), 0.6-1.3 for Caton-Deschamps Index) $(7,20,23)$, and one reported an elevated mean Insall-Salvati of 1.5 (19). Many functional scores were used, but the most frequent was the Lysholm score (26). This score initially described to evaluate function of the knee after anterior cruciate ligament rupture, is routinely used in many knee injurieS $(27,28)$. In our review, Lysholm score ranged from 84 to 95 . It highlights excellent functional capacity subjectively reported by the patients.

Concerning surgical revision rate, 3 studies reported a total of 5 cases of re-ruptures: 3 cases of re-rupture after a fall at 5 weeks (29), 2 months (77) and 4 months (29); 1 re-rupture at 12 months during training in a professional football player (17), 1 re-repture at 2 months revealed by a progressive extension deficit (29). The other studies stated that no case of re-rupture occurred.

\section{DISCUSSION}

In this review, we aimed to focus exclusively on patellar tendon ruptures occurring in patients practicing sport in order to evaluate their ability to return to sport. Indeed, patellar tendon ruptures are usually described in other contexts, especially in middle aged patients with inflammatory or metabolic disease $(9,11)$. In the sport population, data are lacking, and ruptures remain infrequent despite the high frequency of patellar tendinopathy (6). Patellar tendon rupture is a dramatic injury responsible for a complete dysfunction of extensor apparatus of the knee that leads to a surgical procedure and a rehabilitation period (30). As far as we know, the consequences of patellar tendon rupture in terms of return to sport and its management have never been specifically assessed.

According to the features of the studies reviewed, it seems that a wide proportion of patients did not report any medical history that could have weakened their patellar tendon before the rupture. It may appear surprising for 2 reasons. Firstly, these findings seem contradictory with the generally accepted idea that a healthy tendon does not break. Indeed, Zernicke et al. showed that a force 17.5 times supe- 
Table IV. Follow-up and long-term results.

\begin{tabular}{|c|c|c|c|c|c|c|}
\hline \multirow[b]{2}{*}{ Studies } & \multirow[b]{2}{*}{$\begin{array}{c}\text { Mean } \\
\text { follow-up } \\
\text { (months) }\end{array}$} & \multirow[b]{2}{*}{$\begin{array}{c}\text { Return to sport } \\
\text { n (\%) }\end{array}$} & \multicolumn{4}{|c|}{ Complementary evaluation criteria } \\
\hline & & & Range of motion & Functional scores & $\begin{array}{c}\text { Knee } \\
\text { pain }\end{array}$ & $\begin{array}{l}\text { Radiographic } \\
\text { assessment } \\
\text { (CDI or ISI) }\end{array}$ \\
\hline Roudet et al. (2015) & 111,5 & $20(87 \%)$ & $\begin{array}{l}\text { Symmetry with healthy } \\
\text { side: extension }(100 \%) \text {, } \\
\text { flexion }(78 \%)\end{array}$ & Lysholm: 93,7 & 2 & CDI: 0,91 \\
\hline Casey et al. (2001) & 24 & $3(75 \%)$ & $0^{\circ}-112^{\circ}$ & - & 3 & 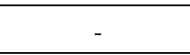 \\
\hline Boublik et al. (2011) & - & $22(100 \%)$ & Full & 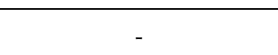 & - & 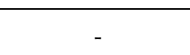 \\
\hline Maffulli et a.l (2017) & - & $5(62.5 \%)$ & $3^{\circ}-112^{\circ}$ & Cincinnati: 84 & 3 & ISI: 1,5 \\
\hline Enad et al. (2001) & 24 & $11(85 \%)$ & $\begin{array}{l}\text { Mean extension deficit: } \\
-1^{\circ}\end{array}$ & Lysholm: 84 & 8 & ISI: 1,16 \\
\hline Marder et al. (1999) & 31 & $14(100 \%)$ & $\begin{array}{c}\text { Mean deficit: extension: } \\
0^{\circ} \text {, flexion: } 5^{\circ} \\
\end{array}$ & Lysholm: 95 & 5 & ISI: 1,09 \\
\hline Kuechle et al. (1994) & 77 & $5(100 \%)$ & Symmetric & $\begin{array}{c}\text { Kelly's scale: } 5 \\
\text { excellent (including } \\
\text { bilateral rupture) }\end{array}$ & 1 & - \\
\hline Bushnell et al. (2008) & 29 & $11(79 \%)$ & $1^{\circ}-133^{\circ}$ & - & - & - \\
\hline Kasten et al. (2001) & 97 & $15(52 \%)$ & From $0^{\circ}-130^{\circ}$ to $0^{\circ}-137^{\circ}$ & $\begin{array}{l}\text { Hospital for special } \\
\text { knee surgery score: } \\
\text { from } 92 \text { to } 96 \text { points }\end{array}$ & 13 & - \\
\hline
\end{tabular}

CDI: Caton-Deschamps Index; ISI: Insall-Salvati Index

rior to the body weight was necessary to break off a patellar tendon (31). Moreover, Josza et al. found in a histopathological study that, amongst 70 ruptures of patellar tendons, none of them were "healthy tendons" (32). In this histopathological study, the authors focused on the spontaneous ruptures, defined as "ruptures that occur during movement and activity, that should not and usually do not damage the involved musculotendinous units". Secondly, jumper's knee is very frequent in high level athletes (6), but only $5 \%$ of the patients with a patellar rupture reported a history of jumper's knee (4). It may be explained by the fact that some subjects may have practiced sports with many jumps responsible for a non-disabling jumper's knee history (stage 1 and 2 of Blazina classification of jumper's knee), and consequently did not report it (33). On a histopathological level, Cook et al (34) showed that, amongst a population of athletes who underwent surgical repair of ACL injury using a patellar tendon graft and without any prior anterior knee pain, different features of tendinopathy could be found, such as tenocytes changes, disrupted collagen and increased ground substance, the most frequent being tenocyte changes. Similarly, Giacchino et al. showed using ultrasound imaging, a high prevalence of subclinical patellar tendinopathy in male throwers free from neuromuscular or skeletal pathology (35).
We found a return to sport that ranged from 52 to $100 \%$. Nguyen et al. reported a rate of $75 \%$ return to pre-injury level in 12 professional NBA players with patellar tendon tears (complete and incomplete) (36). However, these professional players presented a significant decrease in their total number of minutes played per season, 2 seasons after injury. As a comparison, in anterior cruciate ligament rupture, the return to play after ACL reconstruction is $82 \%$ (37) and in Achilles tendon rupture, the return to play after repair is $80 \%$ (38).

Unfortunately, the average time to return to play was rarely specified. Marder et al. reported a mean time of 8.0 months for competitive athletes and 11.5 months for recreational athletes (20). Kelly et al. reported a mean time of 5 to 8 months in thirteen athletes that ruptured their patellar tendon mainly in basketball practice (9 out of 13) (39). This study highlights the same tendency for the more active competitors to return to sport earlier $(5$ months for professionals, 8 months for amateurs participating 1-3 times days per week). In a pediatric population with $80 \%$ of ruptures that occurred during a sport practice, Ali Yousef et al. reported a mean time of return to sport of 5 months (range 13-30 weeks) (40).

The delay of return to sport may vary partially according to the type of rehabilitation program. Indeed, programs could vary from a study to another, and are usually not precisely 
described. An immobilization of 6 weeks is often substituted with an early mobilization, in order to accelerate rehabilitation. However, Serino et al. (9) showed a significantly higher adverse event rate with early mobilization, and a tendency to a higher additional surgery rate. Due to the lack of evidence of benefits of an early mobilization, it is difficult to provide recommendations. The rehabilitation protocol should be chosen individually, taking into account a history or not of patellar tendon tendinopathy, the mechanism of the rupture (high or low intensity), the type of surgical procedure and the patient's wish to return to sport (2).

In our review, we observed that the return to sport outcome was rarely described in the studies. Furthermore, pre-injury level of sport was not specified in most articles. Amongst the few that did precise pre-injury level, many different statuses were reported: professionals, high-school players, collegiate athletes, competitive, recreational competitive and recreational athletes $(17,19-21)$.

Our review has also some limits. Firstly, the major limit is the low level of evidence of the studies included. Indeed, due to the rarity of this affection, there is no randomized controlled study available in the literature (41). In our research, we found a large number of case reports mainly mentioning patients with inflammatory or metabolic diseases, and rarely dealing with a sport practice. Moreover, we observed that, amongst the few case reports mentioning a sport practice, a return to sport was achieved for all of them. Successful treatments being more frequently reported than failures, we did not include case reports, to avoid this bias. However, the main quality of our study is the methods of research, with a wide and quite exhaustive data collection. Secondly, we did not provide a comprehensive assessment of the type of surgical procedures because it has already been studied $(4,30)$. Acute surgical repair is linked with lower complications and higher functional outcomes (4). The type of repair depends on the location of the tear (proximal avulsion, distal avulsion, or mid-substance tear) and on the acute or chronic features of ruptures (chronic ruptures often require tendon reconstruction using auto- or allografts) (30).

\section{REFERENCES}

1. Negrin LL, Nemecek E, Hajdu S. Extensor mechanism ruptures of the knee: differences in demographic data and long-term outcome after surgical treatment. Injury. 2015;46:1957-63.

2. Pengas IP, Assiotis A, Khan W, Spalding T. Adult native knee extensor mechanism ruptures. Injury. 2016;47:2065-70.

3. Clayton RAE, Court-Brown CM. The epidemiology of musculoskeletal tendinous and ligamentous injuries. Injury. 2008;39:1338-44.
In order to improve the quality of future researches regarding patellar tendon ruptures, we cannot advocate the use of a randomized controlled trial. Indeed, because of the rarity of this injury, we would probably be unable to gather enough patients in such a study. Yet, we recommend a more standardized and systematic report of crucial criteria used by every physicians during the follow-up such as anthropometric parameters, prior knee medical history, use of treatment, rupture mechanism, delay and type of surgery, rehabilitation protocol, specific sport outcomes (pre- and post-injury level of sport according Tegner activity scale (28) and Kelly's scale (39), delay of return to sport, isokinetic assessment, jump tests) and more general outcomes (radiographic evaluations, range of motion, pain, functional recovery). Thus, the systematic collection of all these elements would allow better comparability between studies.

\section{CONCLUSIONS}

Patellar tendon rupture occurring during sport is a rare injury, despite the frequency of jumper's knee in athletes. In our review about subjects practicing sport, without other risk factors, we found that from 52 to $100 \%$ of the patients returned to sport, which seems good and close to other lower limb injuries such as ACL or Achilles tendon ruptures. However, our conclusions are really restricted due to the studies' low level of evidence. These results highlight the need of a more systematic and standardized report of crucial data in order to improve quality and comparability of future assessments.

\section{ACKNOWLEDGEMENTS}

The authors would like to thank Mrs. Annie Chailloux for proofreading the article.

\section{CONFLICT OF INTERESTS}

The authors declare that they have no competing interest

4. Gilmore JH, Clayton-Smith ZJ, Aguilar M, Pneumaticos SG, Giannoudis PV. Reconstruction techniques and clinical results of patellar tendon ruptures: Evidence today. The Knee. 2015;22:148-55

5. Blazina ME, Kerlan RK, Jobe FW, Carter VS, Carlson GJ. Jumper's knee. Orthop Clin North Am. 1973;4:665-78.

6. Lian OB, Engebretsen L, Bahr R. Prevalence of jumper's knee among elite athletes from different sports: a cross-sectional study. Am J Sports Med. 2005;33:561-7. 
7. Roudet A, Boudissa M, Chaussard C, Rubens-Duval B, Saragaglia D. Acute traumatic patellar tendon rupture: Early and late results of surgical treatment of 38 cases. Orthop Traumatol Surg Res. 2015;101:307-11.

8. Kasten P, Schewe B, Maurer F, Gösling T, Krettek C, Weise $\mathrm{K}$. Rupture of the patellar tendon: a review of 68 cases and a retrospective study of 29 ruptures comparing two methods of augmentation. Arch Orthop Trauma Surg. 2001;121:578-82.

9. Serino J, Mohamadi A, Orman S, et al. Comparison of adverse events and postoperative mobilization following knee extensor mechanism rupture repair: A systematic review and network meta-analysis. Injury. 2017;48:2793-99

10. Noyes FR, Barber SD, Mooar LA. A rationale for assessing sports activity levels and limitations in knee disorders. Clin Orthop 1989;238-49.

11. Garner MR, Gausden E, Berkes MB, Nguyen JT, Lorich DG. Extensor Mechanism Injuries of the Knee: Demographic Characteristics and Comorbidities from a Review of 726 Patient Records. J. Bone Joint Surg Am. 2015;97:1592-6.

12. Moher D, Liberati A, Tetzlaff J, Altman DG. Preferred Reporting Items for Systematic Reviews and Meta-Analyses: The PRISMA Statement. PLoS Med. 2009;6:6.

13. Guyatt GH, Oxman AD, Vist GE, et al. GRADE: an emerging consensus on rating quality of evidence and strength of recommendations. BMJ. 2008;336:924-6.

14. Cowan J, Lozano-Calderón S, Ring D. Quality of prospective controlled randomized trials. Analysis of trials of treatment for lateral epicondylitis as an example. J. Bone Joint Surg Am. 2007;89:1693-9.

15. Kim JM, Zimmerman RM, Jones CM, Muhit AA, Higgins JP, Means KR. The quality of randomised controlled trials involving surgery from the hand to the elbow: a critical analysis of the literature. Bone Jt J. 2017;99-B:94-9.

16. Coleman BD, Khan KM, Maffulli N, Cook JL, Wark JD. Studies of surgical outcome after patellar tendinopathy: clinical significance of methodological deficiencies and guidelines for future studies. Scand. J Med Sci Sports. 2000;10(1):2-11

17. Boublik M, Schlegel T, Koonce R, Genuario J, Lind C, Hamming D. Patellar tendon ruptures in National Football League players. Am J Sports Med. 2011;39:2436-40.

18. Kasten P, Schewe B, Maurer F, Gösling T, Krettek C, Weise K. Rupture of the patellar tendon: a review of 68 cases and a retrospective study of 29 ruptures comparing two methods of augmentation. Arch Orthop Trauma Surg. 2001;121:57882.

19. Maffulli N, Buono AD, Oliva F. Ipsilateral hamstring tendon graft reconstruction for chronic patellar tendon ruptures: surgical technique. Muscles Ligaments Tendons J. 2017;7:157-62.

20. Marder RA, Timmerman LA. Primary repair of patellar tendon rupture without augmentation. Am J Sports Med. 1999;27:304-7.

21. Kuechle DK, Stuart MJ. Isolated rupture of the patellar tendon in athletes. Am J Sports Med. 1994;22:692-5.

22. Clark SC, Jones MW, Choudhury RR, Smith E. Bilateral patellar tendon rupture secondary to repeated local steroid injections. J Accid Emerg Med. 1995;12:300-1.
23. Enad JG, Loomis LL. Primary patellar tendon repair and early mobilization: results in an active-duty population. J South Orthop Assoc. 2001;10:17-23.

24. Insall J, Salvati E. Patella position in the normal knee joint. Radiology. 1971;101:101-4.

25. Caton J, Deschamps G, Chambat P, Lerat JL, Dejour H. Patella infera. A propos of 128 cases. Rev Chir Orthop Reparatrice Appar Mot. 1982;68:317-25.

26. Lysholm J, Gillquist J. Evaluation of knee ligament surgery results with special emphasis on use of a scoring scale. Am J Sports Med. 1982;10:150-4.

27. Bengtsson J, Möllborg J, Werner S. A study for testing the sensitivity and reliability of the Lysholm knee scoring scale. Knee Surg Sports Traumatol Arthrosc. 1996;4:27-31.

28. Briggs KK, Kocher MS, Rodkey WG, Steadman JR. Reliability, validity, and responsiveness of the Lysholm knee score and Tegner activity scale for patients with meniscal injury of the knee. J Bone Joint Surg Am. 2006;88:698-705.

29. Bushnell BD, Tennant JN, Rubright JH, Creighton RA. Repair of patellar tendon rupture using suture anchors. J Knee Surg. 2008;21:122-9.

30. Hsu H, Siwiec RM. Patellar Tendon Rupture. StatPearls. Treasure Island (FL): StatPearls Publishing. 2019.

31. Zernicke RF, Garhammer J, Jobe FW. Human patellar-tendon rupture. J Bone Joint Surg Am. 1977;59:179-83.

32. Józsa L, Kannus P. Histopathological findings in spontaneous tendon ruptures. Scand J Med Sci Sports. 1997;7:113-8.

33. Clarsen B, Myklebust G, Bahr R. Development and validation of a new method for the registration of overuse injuries in sports injury epidemiology: the Oslo Sports Trauma Research Centre (OSTRC) overuse injury questionnaire. Br J Sports Med. 2013;47:495-502.

34. Cook JL, Feller JA, Bonar SF, Khan KM. Abnormal tenocyte morphology is more prevalent than collagen disruption in asymptomatic athletes' patellar tendons. J Orthop Res. 2004;22:334-8.

35. Giacchino M, Caresio C, Gorji NE, Molinari F, Massazza G, Minetto MA. Quantitative analysis of patellar tendon size and structure in asymptomatic professional players: sonographic study. Muscles Ligaments Tendons J. 2017;7:449-58.

36. Nguyen MV, Nguyen JV, Taormina DP, Pham H, Alaia MJ. A Comprehensive Return-to-Play Analysis of National Basketball Association Players With Operative Patellar Tendon Tears. Orthop J Sports Med. 2018;6:232596711880047.

37. Ardern CL, Webster KE, Taylor NF, Feller JA. Return to sport following anterior cruciate ligament reconstruction surgery: a systematic review and meta-analysis of the state of play. Br J Sports Med. 2011;45:596-606.

38. Zellers JA, Carmont MR, Silbernagel KG. Return to play post-Achilles tendon rupture: a systematic review and meta-analysis of rate and measures of return to play. $\mathrm{Br} \mathrm{J}$ Sports Med. 2016;50:1325-32.

39. Kelly DW, Carter VS, Jobe FW, Kerlan RK. Patellar and quadriceps tendon ruptures-jumper's knee. Am J Sports Med. 1984;12:375-80.

40. Ali Yousef MA, Rosenfeld S. Acute traumatic rupture of the patellar tendon in pediatric population: Case series and review of the literature. Injury. 2017;48:2515-21. 